\title{
Elevated Temperature Tribology of Cobalt and Tantalum-Based Alloys
}

\author{
T.W. Scharf ${ }^{1}$, S.V. Prasad*, P.G. Kotula, J.R. Michael and C.V. Robino \\ Materials Science and Engineering Center, Sandia National Laboratories, Albuquerque, NM \\ 87185-0889, USA \\ ${ }^{1}$ On faculty sabbatical from the Department of Materials Science and Engineering, The \\ University of North Texas, Denton, TX 76203-5310, USA
}

This paper describes the friction and wear behavior of a $\mathrm{Co}-\mathrm{Cr}$ alloy sliding on a Ta-W alloy. Measurements were performed in a pin-on-flat configuration with a hemispherically tipped Cobase alloy pin sliding on a Ta-W alloy flat from ambient to $430^{\circ} \mathrm{C}$. Focused ion beam-scanning electron microscopy (FIB-SEM) and cross-sectional transmission electron microscopy (TEM) were used to identify the friction-induced changes to the chemistry and crystal structure in the subsurface regions of wear tracks. During sliding contact, transfer of material varied as a function of the test temperature, either from pin-to-flat, flat-to-pin, or both, resulting in either wear loss and/or volume gain. Friction coefficients $(\mu)$ and wear rates also varied as a function of test temperature. The lowest friction coefficient $(\mu=0.25)$ and wear rate $\left(1 \times 10^{-4} \mathrm{~mm}^{3} / \mathrm{N} \cdot \mathrm{m}\right)$ were observed at $430^{\circ} \mathrm{C}$ in argon atmosphere. This was attributed to the formation of a Co-base metal oxide layer (glaze), predominantly $(\mathrm{Co}, \mathrm{Cr}) \mathrm{O}$ with Rocksalt crystal structure, on the pin surface. Part of this oxide film transferred to the wear track on Ta-W, providing a self-mated oxide-on-oxide contact. Once the oxide glaze is formed, it is able to provide friction reduction for the entire temperature range of this study, ambient to $430^{\circ} \mathrm{C}$. The results of this study indicate that glazing the surfaces of Haynes alloys with continuous layers of cobalt chrome oxide prior to wear could protect the cladded surfaces from damage. 
*Corresponding author: svprasa@ sandia.gov

Keywords: sliding wear; high temperature wear; cobalt alloys; tantalum alloys; glaze layer

\section{Introduction}

Tantalum-tungsten refractory metal alloys are well known for their high temperature strength while cobalt-chromium alloys, such as Haynes 25, exhibit superior resistance to oxidation at elevated temperatures. Therefore, $\mathrm{Co}-\mathrm{Cr}$ alloys are cladding candidates for providing elevated temperature oxidation protection for Ta-W structures. The major focus of this study was to evaluate the friction and wear behavior, especially during run-in, of Co-Cr/Ta$\mathrm{W}$ contacts at elevated temperatures, and to analyze the tribochemistry (i.e., formation of protective oxide glazes), friction-induced structures and phase transformations in the surfaces and subsurfaces.

Friction and wear mechanisms at elevated temperatures are more challenging to evaluate than those at ambient temperature, as wear mechanisms typically change and can be more complex with increasing temperatures. Peterson et al [1] performed one of the earliest studies on high temperature metallic wear with self-mated metallic pairs of cobalt, iron, copper, nickel and molybdenum. This study revealed that friction and wear could be significantly reduced whenever soft, low interfacial shear strength metallic oxide films form at elevated temperatures. High temperature (up to $800^{\circ} \mathrm{C}$ ) sliding tests on $\mathrm{Ni}-20 \%$ Cr-base alloys (Nimonic 80A) have been shown to induce the formation of oxide 'glaze' surface layers that resulted in lowering wear, compaction and sintering of wear debris [2]. There are also other studies that show softer oxide glazes form during high temperature sliding of Co-based alloys resulting in decreased wear rates [3-5]. Typically, wear rates as a function of sliding temperature exhibit non-linear behavior, 
deviating from Archard's adhesive wear equation that linearly relates hardness and wear resistance.

Recently, Blau [6] reviewed high temperature metallic wear and the effects of oxidation, its role in debris formation, and microstructural evolution during metallic wear. Depending upon the nature of oxide layer formation, the wear rate at elevated temperatures can either be enhanced or reduced. In the case of alumina sliding on nickel aluminide, the wear rate decreased by several orders of magnitude at $650^{\circ} \mathrm{C}$ compared to room temperature, because of the combination of increased yield strength, work hardening of nickel aluminide, and formation of a protective $\mathrm{NiO}$ surface layer at this temperature [6]. Conversely, if the particle layers are not very well compacted (through sintering for example), the relatively loose hard particles are removed more easily and wear rates increase, as in the case of self-mated nickel-base alloy Nimonic 80A [7]. As the temperature increases, the tendency to form stable oxide transfer layers and mechanically mixed layers between rubbing counterbodies becomes paramount in protecting the underlying bulk alloy.

A common theme that emerges from these and other elevated temperature studies is the ability to form, maintain, and if necessary, self-replenish oxide films if long-lasting, low-friction, wear contacts at high temperatures are to be realized. In addition to external heat, frictional heat generated at the sliding contact needs to be considered, since both contributions can influence the high temperature tribological behavior and the ability to form and retain surface oxide layers. Therefore, the major objectives of this study were to 1) quantify the friction coefficients and wear rates of Co-base alloy sliding on Ta-W alloy from ambient to $430^{\circ} \mathrm{C} 2$ ) characterize the sliding-induced chemical and structural changes of the worn surfaces and subsurfaces that control the tribological properties, and 3) determine the friction and wear mechanisms, including 
tribochemical phases (oxide formation), wear-induced phase transformations, grain refinement, and dislocation structures. Understanding these phenomena and their role in controlling the friction and wear behavior of cobalt and tantalum-based alloys are the major focus of this study.

\section{Materials}

Hemispherically tipped Co-base Haynes 25 alloy pins $(\sim 1.59 \mathrm{~mm}$ diameter) with a tip radius of $\sim 0.6 \mathrm{~mm}$ were lapped to achieve an average surface roughness $\left(\mathrm{R}_{\mathrm{a}}\right)$ of $0.094 \mu \mathrm{m}$. Table 1 lists the composition and room temperature mechanical properties of the Haynes 25 alloy. A representative 3D optical white light interferometer image of the polished pin surface is shown in Fig. 1a. A focused ion beam (FIB) cross-section of the pin taken at the spherical cap surface was used to determine if there were any polishing-induced subsurface structural changes. Fig. 1b shows the corresponding cross-sectional bright field transmission electron microscopy (BFTEM) image. Grain refinement due to polishing is localized in the top $\sim 50 \mathrm{~nm}$ resulting in a very thin superficial layer suggesting minimal surface deformation occurred due to polishing. Furthermore, the inset in Fig. 1b shows a selected-area electron diffraction pattern (SADP), which along with the BFTEM image, confirmed that there was no evidence of a FCC to HCP stress-induced transformation in the Co-base alloy due to polishing often observed when such alloys are mechanically cold worked [8]. The Ta-W alloy flats $(22 \times 22 \mathrm{~mm}$ size $)$ were also polished to a $R_{a}=0.25 \mu \mathrm{m}$ against the surface lay and $0.05 \mu \mathrm{m}$ with the lay. Table 1 also lists the composition and room temperature mechanical properties of the Ta-W alloy. Fig. 2a shows a representative 3D optical white light interferometer image of the polished Ta-W flat surface. The slight surface lay due to polishing is evident from the image. A corresponding cross-sectional BFTEM image of the Ta-W flat after polishing is shown in Fig. 2b. Similar to the Co-base alloy pins, there is minimal subsurface plastic deformation due to polishing. The image was acquired 
within a Ta-W grain and shows some evidence of dislocation substructure. These images of the Co-base alloy pin and Ta-W flat will serve as a baseline when compared to the subsurfaces generated during the wear processes.

\section{Experimental Methods}

Sliding friction and wear tests were conducted using a homebuilt linear wear tester (LWT) that was retrofitted to accommodate the heating stage, shown in Fig. 3. The pin (Co-base alloy)-on-flat (Ta-W) configuration within the LWT is indicated on Fig. 3. Experiments were performed at $25^{\circ} \mathrm{C}$ (room temperature), $170^{\circ} \mathrm{C}, 430^{\circ} \mathrm{C}$, and thermal cycled from $430^{\circ} \mathrm{C} \rightarrow 40^{\circ} \mathrm{C} \rightarrow 170^{\circ} \mathrm{C}$. These conditions are referred to hereafter as ambient, $170^{\circ} \mathrm{C}, 430^{\circ} \mathrm{C}$, and thermal cycled, respectively. The ambient tests were run in either laboratory air with approximately $15 \%$ relative humidity $(\mathrm{RH})$ or in $\mathrm{Ar}(0.3 \% \mathrm{RH},<10 \mathrm{ppm} \mathrm{O}$, and $<100 \mathrm{ppm}$ $\mathrm{H}_{2} \mathrm{O}$ ) in an environmental chamber, while the elevated and thermally cycled temperature tests were conducted in Ar only. Reciprocating/bidirectional sliding was performed so that the pin never left contact with the flat thus minimizing any heat losses and pre-oxidation effects. The sliding speed was $3.7 \mathrm{~mm} / \mathrm{sec}$, track length was $\sim 1.7 \mathrm{~mm}$, and each test was carried out to 100 sliding cycles. A Macor ${ }^{\circledR}$ (glass-ceramic) arm, shown in Fig. 3, insulated the load cell from the heat source. A thermocouple placed on the Ta-W flat near the pin measured the temperature throughout testing. Prior to running the friction experiment, an underlying cartridge element was used to heat the Ta-W flat to the desired temperature. The Co-base alloy pin was then brought into contact with the flat and allowed to equilibrate for $\sim 5$ minutes before starting the experiment. The thermal cycled test was conducted to understand the stability of surface oxide glazes. In this series, the first segment of the test was conducted at $430^{\circ} \mathrm{C}$ for 500 cycles and the LWT was cooled to $40^{\circ} \mathrm{C}$ by turning off the heater while keeping the pin in contact with the flat; 
this temperature was chosen since it required too much time to cool to ambient. The test was continued at $40^{\circ} \mathrm{C}$ for another 500 cycles on the same wear track. During the final segment, the disk was heated to $170^{\circ} \mathrm{C}$ and test was run for another 500 cycles. Normal load (W) was applied by deadweights and friction force (F) was measured by a transducer (Sensotec) in the load arm (Fig. 3) where F/W is the friction coefficient $(\mu)$. The load cell has very high sensitivity to measure $\mathrm{W}$ down to $500 \mu \mathrm{N}$. Normal load was $1 \mathrm{~N}$ corresponding to an initial maximum Hertzian contact pressure of 1.5 GPa. At least three tests were conducted for each experimental condition and measurements were made perpendicular to the previously mentioned Ta-W surface lay.

After friction and wear testing, the wear volumes of the Co-base alloy pins and Ta-W flats were characterized by 3D scanning white light interferometry (SWLI) using a Wyko NT1100 optical white light interferometer. Both wear loss (removed material) and volume gain (transferred material) were calculated based on these volumes $\left(\mathrm{mm}^{3}\right)$, then divided by applied normal load $(\mathrm{N})$ and multiplied by total sliding distance $(\mathrm{m})$ to give wear rates in units of $\mathrm{mm}^{3} / \mathrm{N} \cdot \mathrm{m}$. The worn pins and flats were also characterized by scanning electron microscopy (SEM) with energy-dispersive x-ray spectrometry (EDS), and cross-sectional BFTEM with EDS spectral imaging and SADP. High-angle annular dark field scanning TEM (HAADF-STEM) was also used for Z-contrast imaging. Cross-sectional TEM specimens were prepared via FIB, and then analyzed in a TEM/STEM operated at $300 \mathrm{kV}$. Site specific FIB samples were taken close to the center of the Co-base alloy pin contact area and on the Ta-W wear track parallel to the sliding direction. To protect the wear surfaces from ion beam damage, surfaces were first coated with platinum prior to FIB milling and a conservative low $5 \mathrm{kV}$ polish was used during the final milling step. Friction and wear-induced changes to the chemistry, microstructure and 
crystallography in the worn subsurface regions were analyzed with cross-sectional TEM and EDS analyses. X-ray spectral images were collected from wear subsurfaces and then analyzed using Sandia's Automated eXpert Spectral Image Analysis (AXSIA) software [9]. AXSIA quickly reduces large raw spectral images to a compact solution consisting of a small number of linearly independent component image/spectrum pairs. For display purposes, the component images were combined into a color overlay.

\section{Results}

\subsection{Friction and wear}

Figure 4 shows typical friction coefficients as a function of sliding cycles for ambient (air and $\mathrm{Ar}$ ), $170^{\circ} \mathrm{C}$, and thermal cycled tests. Table 2 summarizes the steady-state friction coefficients and wears rates. SWLI images of wear surfaces on the pins and flats are shown in Fig. 5. As shown in Fig. 4a, testing environment at room temperature played a minor role where the averaged steady state friction coefficient in ambient air was slightly lower $(\sim 0.45)$ compared to $\operatorname{Ar}(\sim 0.67)$, although the wear rates listed in Table 2 were slightly lower in Ar. During both ambient tests, the Co-base alloy pin exhibited wear loss (Fig. 5a) while there was corresponding volume gain on the Ta-W flat (Fig. 5b). Due to the transfer of Co-base alloy pin material to the Ta-W wear track, the wear loss and volume gain values listed in Table 2 are roughly equivalent for each ambient testing environment. Since when comparing the friction and wear behavior for ambient air and Ar tests there is relatively good agreement, the ambient air test results will be elaborated on and compared to the high temperature tests hereafter. In addition, the change in shape of the pin (Fig. 5a) during the course of the test increases the apparent area of contact with the flat, thus corresponding to a decrease in contact pressure. For example, one test that started 
with an initial contact pressure of $1.5 \mathrm{GPa}$ decreased to an apparent final pressure of $39 \mathrm{MPa}$. This latter pressure represents a lower limit estimate since it infers that the entire wear flat was in apparent contact with the Ta-W. Despite these changes in the shape of the pin and contact pressures, the steady-state friction coefficients and wear rates listed in Table 2 did not vary significantly. Therefore, there was no contact load/pressure dependency on friction coefficient and wear rates.

The steady-state friction coefficients at $170^{\circ} \mathrm{C}$ are significantly higher than those at ambient temperature, $\sim 1.1$ versus $\sim 0.45$ (Fig. $4 \mathrm{a}$ ). Also in contrast to ambient testing, there is TaW material transfer to the Co-base alloy pin, resulting in a net volume gain as shown in Fig. 5c. Correspondingly, there is a large amount of Ta-W flat wear loss as shown in Fig. 5d. This Ta-W flat wear loss rate is an order of magnitude larger than the wear loss rate of Co-base alloy pin during ambient sliding. Furthermore, Table 2 shows that the wear loss volume on Ta-W (Fig. 5d) is not equal to the volume gain on the pin (Fig. 5c). This is mainly due to wear debris pileup along the edges and at the ends of the track that was not accounted for in the volume gain analysis of the pin. In addition to the change in how material is transferred between the pin and the flat, the large increase in the steady friction coefficient to $\sim 1.1$ and increasing wear rates at $170^{\circ} \mathrm{C}$ suggests that the wear mechanisms at ambient and at $170^{\circ} \mathrm{C}$ are different, and will be discussed in the next section.

The friction coefficient averaged across the first 100 cycles of sliding at $430^{\circ} \mathrm{C}$ was $\sim 0.75$. However, extending the test to 500 cycles revealed a clear transition in the coefficient of friction from 0.75 to 0.25 after approximately 200 cycles (Fig. 4b). No such friction transitions were noted during a thermally 300 -cycled test from $170^{\circ} \mathrm{C}$ to ambient where the friction coefficient remained at $\sim 1.1$.. The friction coefficient remained at this low value $(0.25)$ even 
when the same wear track was tested at $40^{\circ} \mathrm{C}$ and $170^{\circ} \mathrm{C}$. Also worth noting is that the friction coefficient at $170^{\circ} \mathrm{C}$ from this thermally cycled test is significantly lower than the value on the virgin surface (Fig. 4a). These findings imply that the surface chemistry and structure generated during wear at $430^{\circ} \mathrm{C}$ testing was responsible for the reduction in friction at ambient and intermediate temperatures. Figs. 5e and 5f show the 3D SWLI images of the Co-base alloy pin with both wear loss and volume gain (transferred Ta-W) and the Ta-W wear track, respectively, after $430^{\circ} \mathrm{C}$ testing. In this case, measurement of a Ta-W flat wear rate was difficult because there was minimal and insignificant difference between wear loss and volume gain in the track. In contrast to $170^{\circ} \mathrm{C}$ testing, there is much less (an order of magnitude) Ta-W material transfer (volume gain) to the Co-base alloy pin and barely any wear on the Ta-W flat. As in ambient testing, there is some wear loss of Co-base alloy pin, but there is more Ta-W transfer to the pin at $430^{\circ} \mathrm{C}$. Lastly, the Co-base alloy pin wear rates from the thermal cycled test were calculated to be $1.3 \times 10^{-4} \mathrm{~mm}^{3} / \mathrm{N} \cdot \mathrm{m}$ (wear loss) and $1.5 \times 10^{-5} \mathrm{~mm}^{3} / \mathrm{N} \cdot \mathrm{m}$ (volume gain), both comparable to the $430^{\circ} \mathrm{C}$ test values listed in Table 2 . This further supports the observation that the wear surfaces formed during the $430^{\circ} \mathrm{C}$ portion of the thermal cycled test are present for the remaining 1000 sliding cycles.

\subsection{Wear surface analysis}

The worn surfaces previously shown by the 3D SWLI images in Fig. 5 were analyzed by SEM and EDS. Fig. 6 shows an (a) SEM image and (b) corresponding EDS map of the wear flat on the Co-base alloy pin after ambient sliding (acquired from worn surface in Fig. 5a). Fig. 6a clearly shows that grooves on the pin are aligned parallel to the sliding direction, indicative of micro-abrasive wear. There is no clear detectable adhesive transfer of Ta-W to Co-base alloy with the exception of a few, small un-oxidized Ta-W wear particles shown in purple on the EDS 
map in Fig. 6b. The 'square' feature on the wear surface is the location of a FIB-cut that will be discussed in the next section. The corresponding SEM image of the mating Ta-W wear track shown in Fig. 6c is acquired from the worn surface in Fig. 5b. Wear debris is generated on the surface, although it is not completely conformal across the track. The 3D optical profilometry determined that the wear debris was only on the high contact points (peaks) in the track, i.e., the non-contacting points (valleys) along the vertical surface lay were unworn/untouched Ta-W, and thus did not generate wear debris. If the track had lower surface roughness against the lay, i.e., $\mathrm{R}_{\mathrm{a}}<0.25 \mu \mathrm{m}$ shown in Fig. 2a, then more conformal coverage of the wear debris would more likely have been observed along the track. EDS maps in Fig. 6d confirm that this wear debris is transferred material from the Co-base alloy pin that resulted in volume gain shown previously in Fig. 5b. Baseline Ta and W (not shown) EDS maps show Ta-W is present everywhere except in the 'black' regions in the track which is the wear debris. EDS maps show that the debris is made up of oxidized Co-base alloy alloying elements, mostly $(\mathrm{Co}, \mathrm{Cr})$ oxide (Cr map not shown but is identical to Co map). This oxide layer is a tribochemical phase, generated from transfer from the Co-base alloy pin, and is non-continuous due to the surface lay. These high contacting spots in the track represent the real area of sliding contact. Trace amounts of oxygen and water vapor in the environmental chamber, and perhaps within the Ar gas itself, seemed to be all that is required for oxidative wear at room temperature.

Fig. 7 shows an (a) SEM image and (b) corresponding EDS maps of the wear surface on the Co-base alloy pin after $170^{\circ} \mathrm{C}$ sliding (acquired from worn surface Fig. 5c). Unlike the ambient test, there is clear evidence of a transfer film on top of the Co-base alloy pin surface. EDS maps confirm the film is composed of Ta and W (not shown) that transferred from the TaW flat. The transfer film appears relatively un-oxidized based on the oxygen EDS map. The 
corresponding SEM image and EDS maps of the mating Ta-W wear track are shown in Figs. 7c and $7 \mathrm{~d}$, respectively. In contrast to the ambient test, there is more severe wear (galling) in the Ta-W wear track. Instead of oxidized Co-base alloy elements present throughout the wear track, there exists base un-oxidized Ta and W (not shown). It is only absent at some places along the wear track edge where $(\mathrm{Co}, \mathrm{Cr})$ oxide, transferred from the pin, exists, based on the increase in signal from the $\mathrm{Co}, \mathrm{Cr}$ (not shown), and O EDS maps in Fig. 7d. However, since the oxide is not present inside the wear track, it does not contribute to friction and wear reduction as in the ambient test. Based on the images and chemical maps presented in Fig. 7, there is self-mated Ta$\mathrm{W}$ on Ta-W sliding at $170^{\circ} \mathrm{C}$. This interfacial sliding pair accounts for the high friction coefficients and wear rates listed in Table 2 , since the protective Co-base alloy metal oxide layers were not formed on either sliding surface. The absence of the Co-alloy oxide transferring to the Ta-W wear track resulted in the wide, extruded shear lips shown in Fig. 7c. Therefore, extensive adhesive wear and cold welding of high spots occurs across the sliding interface with transfer of Ta and $\mathrm{W}$ to the Co-base alloy pin. The friction coefficient was high and variable (Fig. 4a) indicative of gross cold welding or galling.

Fig. 8 shows an (a) SEM image and (b) corresponding EDS maps of the wear surface on the Co-base alloy pin after $430^{\circ} \mathrm{C}$ sliding (acquired from worn surface in Fig. 5e). In contrast to the ambient test, there is clear evidence of a transfer film on the Co-base alloy pin surface. Furthermore, unlike the results from the $170^{\circ} \mathrm{C}$ experiments, the film is not composed of Ta and W directly transferred from the Ta-W flat. Instead the transfer film is predominantly oxidized Co-base alloy elements, mostly $(\mathrm{Co}, \mathrm{Cr})$ oxide with a small patch of transferred $(\mathrm{Ta}, \mathrm{W})$ oxide based on the EDS maps in Fig. 8b. Additionally, there is a stronger oxygen signal from the transfer film compared with the measurement after the ambient test due to tribo-oxidation at 
elevated temperatures, even in the presence of Ar. Surface profilometry determined that the oxide layers form on the high contact spots. The two 'square' features on the wear surface show the location of FIB-cuts that will be discussed in the next section. The corresponding SEM image and EDS maps of the mating Ta-W wear track are shown in Figs. 8c and 8d, respectively. Similar to the ambient test, Co-base alloy oxide, mostly $(\mathrm{Co}, \mathrm{Cr})$ oxide, has tribochemically formed on the Ta-W wear track by transfer of Co-base alloy pin to the high contact spots. Thus, the low friction coefficients and wear rates at $430^{\circ} \mathrm{C}$ (Table 2 and Fig. $4 \mathrm{~b}$ ) are a result of selfmated Co-base alloy oxide layers (predominantly $\mathrm{Co}, \mathrm{Cr}$ oxide) on both sliding surfaces that protects the underlying Ta-W from wear. The lower friction at $430^{\circ} \mathrm{C}$ than in the ambient test is due to more conformal (and thicker) alloy $(\mathrm{Co}, \mathrm{Cr})$ oxide layer on the pin. Not shown are the wear surfaces after the thermal cycled test from Fig. 4b. They are similar to Fig. 8 images and maps, and therefore remained stable when cycled back down to $40^{\circ} \mathrm{C}$ and ramped up to $170^{\circ} \mathrm{C}$. This oxide glaze on the pin is thus thermally stable and leads to low friction and wear.

\section{Discussion}

Structural and chemical subsurface analyses were performed on the sliding pairs with cross-sectional TEM and EDS maps. Specifically, the 3D SWLI Co-base alloy pins and Ta-W flats, shown in Fig. 5, were analyzed in cross-section. Figs. 9a and 9b show a cross-sectional BFTEM image and corresponding $x$-ray spectral imaging map, respectively, of the Co-base alloy pin subsurface after ambient sliding (acquired from surface in Figs. 5a and 6a), revealing wearinduced subsurface zones categorized as zones 1,2 and 3 in Fig. 9. The top zone (zone 1) consists of an oxidized Co-base alloy wear debris patch, colored magenta in x-ray spectral imaging map, that also contains a very thin sliver of un-oxidized Ta-W, colored red in x-ray spectral imaging map, suggesting that some mechanically mixing occurred during interfacial 
sliding. The corresponding zone 1 SADP in Fig. 9 shows this oxidized layer is mostly amorphous, based on the diffuse halo ring, intermixed with some oxidized nanocrystalline (nc) size wear debris. The oxide was identified as $(\mathrm{Co}, \mathrm{Cr}) \mathrm{O}$ indexed to the Rocksalt crystal structure with $\mathrm{a}=4.06 \AA$. Beneath this layer, zone 2 is identified. It is composed of un-oxidized Co-base alloy elements, colored blue in x-ray spectral imaging map. This zone is composed of nc-grains and extends to a depth of about $1 \mu \mathrm{m}$. The corresponding SADP in Fig. 9 suggests that the nc grains have some rotational texture. Zone 3, which extends through the remaining FIB-cut depth, shows HCP platelets indicating a wear-induced FCC to HCP transformation in this zone. The corresponding SADP in Fig. 9 confirms the co-existence of both FCC (large spots) and HCP (small spots) structures with $[111]_{\mathrm{FCC}}$ and $[0001]_{\mathrm{HCP}}$ reciprocal lattice intersections. This phase transformation has also been observed in mechanical cold working studies of Co-base alloy (Haynes 25) under various percentages of cold work [8], where it is theorized that platelets of the HCP phase were formed due to the increase in density of stacking faults. In this study, the HCP platelets were generated during sliding. Sliding wear tests under higher normal loads also confirm the FCC to HCP transformation occurred in other Co-base alloys Stellite 21 [10] and Stellite 6B [11]. The inset high resolution TEM image in Fig. 9a shows that the Co (0002) basal planes (d-spacing $\sim 2.0 \AA$ ) are predominantly orientated parallel to the wear surface. Sliding wear tests on Stellite 21 confirmed that increasing Co basal plane alignment occurs under higher normal loads resulting in lowering of friction and wear [10,12]. Since Co-base Haynes and Stellite alloys have low stacking fault energies, planar glide dominates the plastic deformation [13] and slip along self-aligned Co basal planes results in low interfacial shear strengths and friction [12]. The cross-sectional TEM image in Fig. 9a is in sharp contrast to the unworn (polished) Co-base alloy pin subsurface structure shown in Fig. 1b. Furthermore, the subsurface 
EDS map in Fig. 9b correlates well with the surface EDS maps in Fig. 6 where there is some non-continuous oxidized Co-base alloy layers intermixing with un-oxidized Ta-W wear particles.

The wear-induced subsurface evolution of the mating Ta-W flat is shown in Fig. 10. Similar to Fig. 9 for the pin, the entire FIB-liftout shows evidence of plastic deformation (more severe near the surface) compared to unworn (polished) Ta-W shown in Fig. 2b. The FIB crosssection in Fig. 10a was obtained from a portion of the wear track in Fig. 6c that contained transfer of oxidized Co-base alloy. A portion of this $(\mathrm{Co}, \mathrm{Cr})$ oxide layer (Rocksalt structure) transferred to the underlying plastically deformed Ta-W alloy, is shown as zone 1 in Fig. 10a. The corresponding $\mathrm{x}$-ray spectral imaging map of this layer in Fig. 10b shows that the oxygen content varies through thickness (green=less oxygen and magenta=more oxygen). The entire oxide glaze layer is $\sim 3 \mu \mathrm{m}$ thick along this particular cross-section and is layered likely caused by the reciprocating nature of sliding where adhesive transfer and compaction of the glaze occurs with each cycle. There are also small amounts of mechanically mixed Ta-W in the oxidized glaze layer. As in the plastically deformed Co-base alloy pin subsurface, there are several zones of wear-induced structural evolution in the underlying Ta-W. Zone 2 shows a gradient in nc TaW substructures (from $\sim 20 \mathrm{~nm}$ at top to $\sim 200 \mathrm{~nm}$ below) that form forest dislocations which organize into 'brick-shaped lamellar' dislocation cells elongated parallel to the sliding direction. Zone 3 consists of microcrystalline $(\mathrm{mc})$ Ta-W with subgrain structures that extend through the remaining FIB liftout ( $\sim \mu$ m depth). These dislocation cells and subgrain structures may lead to surface hardening by reducing the effective grain size. The corresponding SADP of the three wear zones shown in Fig. 10 confirm that zone 1 is composed of amorphous and nc grain oxidized Co-base alloy with $(\mathrm{Co}, \mathrm{Cr}) \mathrm{O}$ Rocksalt structure. Zone 2 shows more randomly orientated nc grains compared to zone 3 and these nc grains exhibit slight grain rotation during 
sliding. In addition, an SEM-transmission Kikuchi diffraction pattern map, which will be reported in the future, showed that there is no preferred orientation of either the mc or nc Ta-W grains, indicating no sliding-induced texturing of the Ta-W substructures. In summary, the two mating wear subsurfaces in Figs. 9 and 10 show a deformation hardened (FCC to HCP) Co-base alloy pin with small patches of Co-base alloy oxidized wear debris sliding on oxidized Co-base alloy wear layers transferred to the underlying plastically deformed Ta-W flat. Therefore, the oxidized layers are contributing to the reduction in friction coefficients and wear rates listed in Table 2 for ambient sliding.

Similar analyses were performed on Co-base alloy and Ta-W subsurfaces after $170^{\circ} \mathrm{C}$ sliding. Figs. 11a and $11 \mathrm{~b}$ present cross-sectional HAADF-STEM images of the Co-base alloy pin and Ta-W flat wear subsurfaces acquired from Figs. 7a and 7c surfaces, respectively. Fig. 11a shows a $\sim 5 \mu \mathrm{m}$ thick Ta-W transfer film on the Co-base alloy pin along with a mechanically mixed Co-base alloy wear particle (whitish color) that was confirmed by the inset x-ray spectral imaging map (blue color). The Ta-W transfer film is un-oxidized, which is in agreement with the SEM-EDS map in Fig. 7b, and there is no amorphous or nc oxidized Co-base alloy material that was previously shown on the Co-base alloy pin after ambient sliding. The plastically deformed Ta-W transfer film exhibits several wear-induced subsurface zones. Zone 1 has nc Ta-W grains ( $\sim 50-75 \mathrm{~nm}$ size $)$ that are randomly orientated according to the inset SADP. Deeper into the TaW transfer film subsurface, zone 2 shows the existence of dislocation substructures that were previously shown for Ta-W in Fig. 10a after ambient sliding. The mating Ta-W flat is shown in Fig. 11b. The entire FIB cross-section $(\sim 5 \mu \mathrm{m}$ depth) shows a plastically deformed Ta-W wear subsurface. As in ambient sliding, there exist several zones of subsurface plastic deformation. The top surface/near surface zone, denoted by orange color box in Fig. 11b, shows nc Ta-W grain 
refinement. The zone below exhibits coarser platelets further into the subsurface, denoted by purple color box in Fig. 11b. In addition, Ta-W grain rotation occurred as the wear surface is approached according to the inset SADP. Not shown is the $170^{\circ} \mathrm{C}$ cross-sectional subsurface prior to sliding that only exhibits a very thin $(\sim 2-4 \mathrm{~nm}) \mathrm{Ta}_{\mathrm{x}} \mathrm{O}_{\mathrm{y}}$ surface layer. This rules out the contribution of severe oxidation on the Ta-W surface prior to sliding wear. In summary, the two wear subsurfaces in Fig. 11 show self-mated sliding of severe plastically deformed nc and mc TaW that accounts for high friction and wear at $170^{\circ} \mathrm{C}$, since there are no protective oxide glaze layers on either sliding surface. This corroborates the surface EDS maps in Fig. 7 that show the absence of surface metal oxides. It is likely that if an oxide glaze layer did form at $170^{\circ} \mathrm{C}$ that it would be too thin to protect the underlying Ta-W that results in the observed increase in friction coefficient and wear rates. This was the case for self-mated sliding of Haynes Stellite No. 1 at $250^{\circ} \mathrm{C}$ where the oxide glaze was too thin to provide complete protection [14].

Subsurface analyses were also performed on Co-base alloy and Ta-W after $430^{\circ} \mathrm{C}$ sliding. Figs. 12a and 12b show cross-sectional HAADF-STEM images and corresponding x-ray spectral imaging maps of the Co-base alloy pin and Ta-W flat wear subsurfaces acquired from Figs. 8a and 8c surfaces, respectively. Both wear subsurfaces show evidence of thick $(\sim 0.5-1 \mu \mathrm{m})$ transfer films composed predominantly of Co-base alloy oxide with some compositional variation. At $430^{\circ} \mathrm{C}$, all the metals have been oxidized compared to the lower testing temperatures. However, unlike the lower temperature tests, the oxides are much thicker and more continuous across the Co-base alloy pin. The mating Ta-W wear track in Fig. 12b shows that the same thick Co-base alloy oxide layer has transferred to the Ta-W flat, in agreement with SEM-EDS surface maps shown in Figs. 8c and 8d. Therefore, this self-mated oxide-on-oxide glaze on both sliding surfaces accounts for the reduced friction coefficient and wear rates listed 
in Table 2. There are some regions on the oxide glaze transfer film that exhibit Cr-enhanced Haynes oxide as well as a very thin, patchy $\mathrm{Cr}_{\mathrm{x}} \mathrm{O}_{\mathrm{y}}$ surface layer, which may also contribute to lowering the friction and wear. Friction-reducing Cr-rich oxides in the glazes were also determined to form with the stable $\mathrm{Cr}_{2} \mathrm{O}_{3}$ phase when sliding on self-mated Co-base Stellite 31 alloys under similar testing temperatures [4]. Similarly, sliding on Co-base alloy Haynes Stellite No. 1 generates wear debris consisting of $\mathrm{CoO}$ and $\mathrm{Cr}_{2} \mathrm{O}_{3}$ [15]. Not shown is the unworn $430^{\circ} \mathrm{C}$ cross-sectional subsurface prior to sliding that exhibits a very thin $(\sim 3-5 \mathrm{~nm}) \mathrm{Ta}_{\mathrm{x}} \mathrm{O}_{\mathrm{y}}$ surface layer. As in the other high temperature tests, this rules out the contribution of oxidation on the Ta-W surface prior to sliding wear. Lastly, both sliding materials from the thermal cycled test in Fig. 4b exhibit similar self-mating oxide glaze layers on both sliding surfaces and subsurfaces (not shown), although a slightly thicker oxide layer formed on the Ta-W flat. The SADP shown in Fig. 12 confirms the oxide glaze layers are composed of amorphous and nc grain oxidized Cobase alloying elements. In summary, the low friction and wear behavior when sliding Co-base alloy on Ta-W at $430^{\circ} \mathrm{C}$ is due to the lowering of the interfacial shear strength between the selfmated oxide glaze layers, which is supported by the underlying work hardened layers. This follows the soft-on-hard Bowden and Tabor concept for achieving low interfacial sliding friction and wear [16]. In the case of Co-base alloy, hardening occurred due to dislocation storage from cold working as well as the wear-induced FCC to HCP transformation resulting in HCP platelets by stacking fault coalescence during sliding deformation.

\section{Conclusions}

The friction and wear behavior of Co-base alloy sliding on Ta-W has been determined from ambient to $430^{\circ} \mathrm{C}$. Sliding at ambient temperature strain hardened the Co-base alloy due to 
the wear-induced FCC to $\mathrm{HCP}$ transformation resulting in $\mathrm{HCP}$ platelets by stacking fault coalescence in the subsurface regions. Relatively low friction and wear were achieved at ambient sliding due to a non-continuous and thin Co-base alloy oxide, predominantly Rocksalt $(\mathrm{Co}, \mathrm{Cr}) \mathrm{O}$, on the pin that transferred to the Ta-W wear track. The highest friction coefficients and wear rates were exhibited at $170^{\circ} \mathrm{C}$ due to Ta-W sliding on Ta-W, without the formation of a protective $(\mathrm{Co}, \mathrm{Cr}) \mathrm{O}$ layer. Lowest friction and wear was determined at $430^{\circ} \mathrm{C}$ due to thicker and more continuous protective $(\mathrm{Co}, \mathrm{Cr}) \mathrm{O}$ glaze layers on the pin sliding against self-mated oxide glaze layers transferred to the Ta-W wear track. Once the glaze oxide layers are formed at $430^{\circ} \mathrm{C}$, heat transfer to the bulk from the sliding interface may be mitigated, thus reducing the possibility of thermal softening. Results of this study indicate that forming the oxide glaze layers on the surfaces of Co-base alloys prior to their deployment as claddings is desirable and could significantly reduce wear damage.

\section{Acknowledgments}

The authors would like to acknowledge Rand Garfield for design and construction of the high temperature wear tester. We also thank Lisa Marie Lowery, Michael Rye and Garry Bryant for preparing focused ion beam samples, Amy Allen for scanning electron microscopy studies, and Jon-Erik Mogonye for optical profilometry rendering and analysis. The authors also acknowledge Thomas Buchheit for reviewing the manuscript. Sandia National Laboratories is a multi-program laboratory managed and operated by Sandia Corporation, a wholly owned subsidiary of Lockheed Martin Corporation, for the U.S. Department of Energy's National Nuclear Security Administration under contract DE-AC04-94AL85000.

\section{References}


1. M.B. Peterson, J.J. Florek, R.E. Lee, Sliding characteristics of metals at high temperatures, ASLE Trans. 3 (1960) 101-109.

2. F.H. Stott, High-temperature sliding wear of metals, Tribol. Int. 35 (2002) 489-495.

3. P.M. Dunckley, T.F.J. Quinn, J. Salter, Studies of the unlubricated wear of a commercial cobalt-base alloy at temperatures up to about $400^{\circ} \mathrm{C}$, ASLE Trans. 19 (1976) 221-231.

4. F.H. Stott, C.W. Stevenson, G.C. Wood, Friction and wear properties of Stellite 31 at temperatures from 293 to 1073K, Met. Technol. 4 (1977) 66-74.

5. P.D. Wood, H.E. Evans, C.B. Ponton, Investigation into the wear behavior of Stellite 6 during rotation as an unlubricated bearing at $600^{\circ} \mathrm{C}$, Tribol. Int. 44 (2011) 1589-1597.

6. P.J. Blau, Elevated-temperature tribology of metallic materials, Tribol. Int. 43 (2010) 12031208.

7. J. Jiang, F.H. Stott, M.M. Stack, A generic model for dry sliding wear of metals at elevated temperatures, Wear 256 (2004) 973-985.

8. H.M. Tawancy, V.R. Ishwar, B.E. Lewis, On the fcc $\rightarrow$ hcp transformation in a cobalt-base superalloy (Haynes alloy No. 25), J. Mat. Sci. Lett. 5 (1986) 337-341.

9. P.G. Kotula, M.R. Keenan, J.R. Michael, Automated analysis of SEM X-ray spectral images: a powerful new microanalysis tool, Microsc. Microanal. 9 (2003) 1-17.

10. D.H.E. Persson, S. Jacobson, S. Hogmark, The influence of phase transformations and oxidation on the galling resistance and low friction behavior of a laser processed Co-based alloy, Wear 254 (2003) 1134-1140. 
11. M. Sebastiani, V. Mangione, D. De Felicis, E. Bemporad, F.Carassiti, Wear mechanisms and in-service surface modifications of a Stellite 6B Co-Cr alloy, Wear 290-291 (2012) 10-17.

12. S. Jacobson and S. Hogmark, Surface modifications in tribological contacts, Wear 266 (2009) 370-378.

13. M. Knezevic, J.S. Carpenter, M.L. Lovato, R.J. McCabe, Deformation behavior of the cobalt-based superalloy Haynes 25: experimental characterization and crystal plasticity modeling. Acta Mater. 63 (2014) 162-168.

14. P. Crook, C.C. Li, The elevated temperature metal-to-metal wear behavior of selected hardfacing alloys, Wear of Materials, ASME (1983) 272-279.

15. K.J. Bhansali, Adhesive wear of nickel- and cobalt-base alloys, Wear 60 (1980) 95-110.

16. T.W. Scharf, S.V. Prasad, Solid lubricants: a review, J. Mat. Sci. 48 (2013) 511-531.

Table 1. Compositions and room temperature mechanical properties of Co-base (Haynes 25) and Ta-W alloys.

\begin{tabular}{llllll}
\hline Alloy & Compositions (wt\%) & $\begin{array}{l}\text { Hardness } \\
\text { HV10 }(\mathrm{GPa})\end{array}$ & $\begin{array}{l}\text { Elastic } \\
\text { modulus }(\mathrm{GPa})\end{array}$ & $\begin{array}{l}\text { Poisson's } \\
\text { ratio }\end{array}$ & $\begin{array}{l}\text { Tensile strength } \\
\text { UTS (MPa) }\end{array}$ \\
\hline $\begin{array}{l}\text { Haynes } \\
25^{*}\end{array}$ & $\begin{array}{l}51 \mathrm{Co}, 20 \mathrm{Cr}, 15 \mathrm{~W}, 10 \\
\mathrm{Ni}, 1.5 \mathrm{Mn},<3 \mathrm{Fe},<0.4\end{array}$ & 2.55 & 225 & 0.31 & 1015 \\
& $\mathrm{Si}, 0.1 \mathrm{C}$ & & & \\
Ta-W** & $90 \mathrm{Ta}, 10 \mathrm{~W}$ & 1.88 & 207 & 0.30 & 620 \\
& & & & & \\
\hline
\end{tabular}

* Analyses supplied by Haynes International, Inc.

** Analyses supplied by Cabot Supermetals 
Table 2. Summary of friction and wear results for Co-base alloy pin sliding on Ta-W flat (100 cycle tests).

\begin{tabular}{llll}
\hline Condition & $\begin{array}{l}\text { Steady-state } \\
\text { friction coefficient }\end{array}$ & \multicolumn{2}{c}{ Wear rate $\left(\mathrm{mm}^{3} / \mathrm{N} \cdot \mathrm{m}\right)$} \\
\cline { 3 - 4 } & & Co-base alloy & $\mathrm{Ta}-\mathrm{W}$ \\
\hline $\begin{array}{l}\text { Ambient } \\
(15 \% \text { RH air) }\end{array}$ & $0.45 \pm 0.04$ & $3.2 \pm 0.4 \times 10^{-4}$ (wear loss) & $2.3 \pm 0.3 \times 10^{-4}$ (volume gain) \\
$\begin{array}{l}\text { Ambient } \\
(\mathrm{Ar})\end{array}$ & $0.67 \pm 0.09$ & $1.0 \pm 0.2 \times 10^{-4}$ (wear loss) & $1.1 \pm 0.7 \times 10^{-4}$ (volume gain) \\
$170^{\circ} \mathrm{C}$ & $1.1 \pm 0.24$ & $2.9 \pm 0.3 \times 10^{-4}$ (volume gain) & $6.1 \pm 0.3 \times 10^{-3}$ (wear loss) \\
$430^{\circ} \mathrm{C}$ & $0.75 \pm 0.09$ & $1.6 \pm 1 \times 10^{-4}$ (wear loss) + & volume gain $\approx$ wear loss \\
& & $4.7 \pm 3 \times 10^{-5}$ (volume gain) \\
\hline
\end{tabular}

\section{Figure Captions}

Fig. 1. (a) 3D scanning white light interferometry image (units in $\mu \mathrm{m}$ ) and (b) cross-sectional BFTEM image of Co-base alloy pin after polishing (pre-wear). A spherical WC particle is also shown in the subsurface. Inset is a SADP pattern acquired from near surface showing the FCC structure viewed down $\mathrm{ZA}=[011]$.

Fig. 2. (a) 3D scanning white light interferometry image (units in $\mu \mathrm{m}$ ) and (b) cross-sectional BFTEM image of Ta-W flat after polishing (pre-wear).

Fig. 3. High temperature LWT in pin-on-flat configuration.

Fig. 4. Representative friction coefficients of Co-base alloy sliding on Ta-W for (a) ambient (air and $\mathrm{Ar}$ ) and $170^{\circ} \mathrm{C}$ tests, and (b) thermal cycled test.

Fig. 5. 3D SWLI images of Co-base alloy pins on left and Ta-W flats on right for $(a, b)$ ambient (air), (c,d) $170^{\circ} \mathrm{C}$, (e,f) $430^{\circ} \mathrm{C}$ tests. Units in microns.

Fig. 6. (a) SEM image and (b) corresponding EDS map of wear flat on Co-base alloy pin after ambient sliding (images acquired from Fig. 5a surface). (c) SEM image and (d) corresponding EDS maps of wear track on Ta-W flat (images acquired from Fig. 5b surface). Scale bars are 100 $\mu \mathrm{m}$. 
Fig. 7. (a) SEM image and (b) corresponding EDS maps of wear surface on Co-base alloy pin after $170^{\circ} \mathrm{C}$ sliding (images acquired from Fig. 5c surface). (c) SEM image and (d) corresponding EDS maps of wear track on Ta-W flat (images acquired from Fig. 5d surface) taken from area in (c) denoted by red rectangle. Scale bars are $100 \mu \mathrm{m}$.

Fig. 8. (a) SEM image and (b) corresponding EDS maps of wear surface on Co-base alloy pin after $430^{\circ} \mathrm{C}$ sliding (images acquired from Fig. 5e surface). (c) SEM image and (d) corresponding EDS maps of wear track on Ta-W flat (images acquired from Fig. 5f surface) taken from area in (c) denoted by red rectangle. Scale bars are $100 \mu \mathrm{m}$.

Fig. 9. Cross-sectional (a) BFTEM image and SADP of three wear zones taken from FIB-cut location in Fig. 6a, of Co-base alloy pin after ambient sliding, and (b) AXSIA-analyzed x-ray spectral image, acquired from dashed rectangle in (a), of wear surface. Inset in (a) is high resolution TEM image of Co (0002) basal planes orientated parallel to wear surface.

Fig. 10. Cross-sectional (a) HAADF-STEM (top) and BFTEM (bottom) images (separated by the dashed line) with SADP of three wear zones taken from FIB-cut location in Fig. 6c, and (b) AXSIA-analyzed x-ray spectral image ( $3.2 \times 2.4 \mu \mathrm{m}$ size) displayed as color overlay of Co-base alloy oxidized wear layer (top) transferred to Ta-W flat (bottom) after ambient sliding.

Fig. 11. Cross-sectional HAADF-STEM images taken from FIB-cuts on (a) center of Ta-W transfer film on Co-base alloy pin in Fig. 7a, and (b) center of Ta-W wear track in Fig. 7c after $170^{\circ} \mathrm{C}$ sliding. Inset images in (a) show a SADP of the near surface nc-layer and an AXSIAanalyzed $x$-ray spectral image displayed as color overlay. The inset HAADF-STEM images in (b) show higher magnifications of the different subsurface wear zones with corresponding SADP.

Fig. 12. Cross-sectional HAADF-STEM images with SADP and corresponding AXSIA-analyzed $\mathrm{X}$-ray spectral images displayed as color overlays (green boxes in images indicate regions of spectral image acquisition) taken from FIB-cuts on (a) Co-base alloy oxidized wear layer on the un-oxidized pin from Fig. 8a, and (b) mating Co-base alloy oxidized wear layer transferred to Ta-W flat from Fig. $8 \mathrm{c}$ after $430^{\circ} \mathrm{C}$ sliding. Scale bars are $400 \mathrm{~nm}$. 
Click here to download high resolution image

(a)

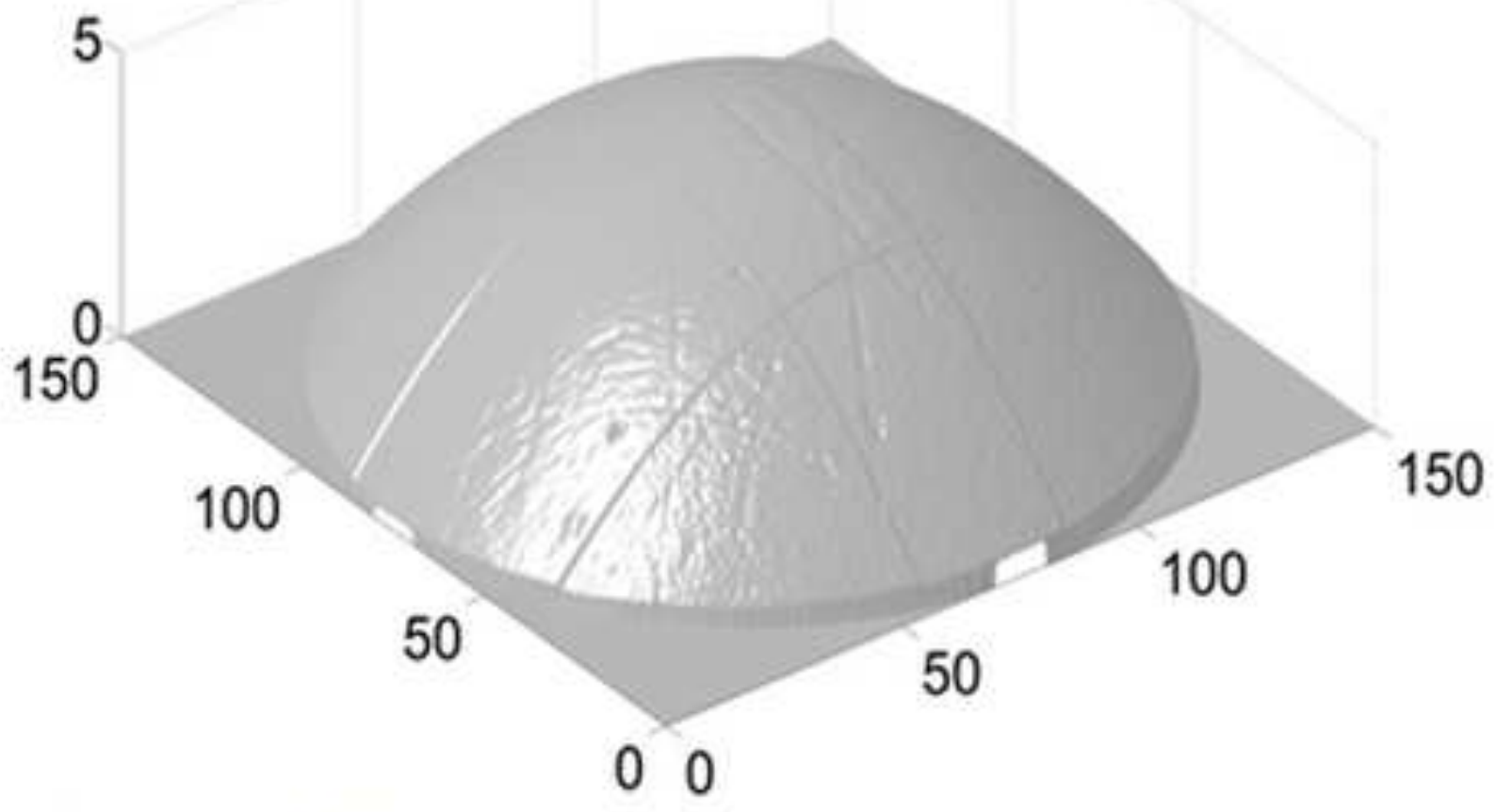

(b) polished spherical cap surface

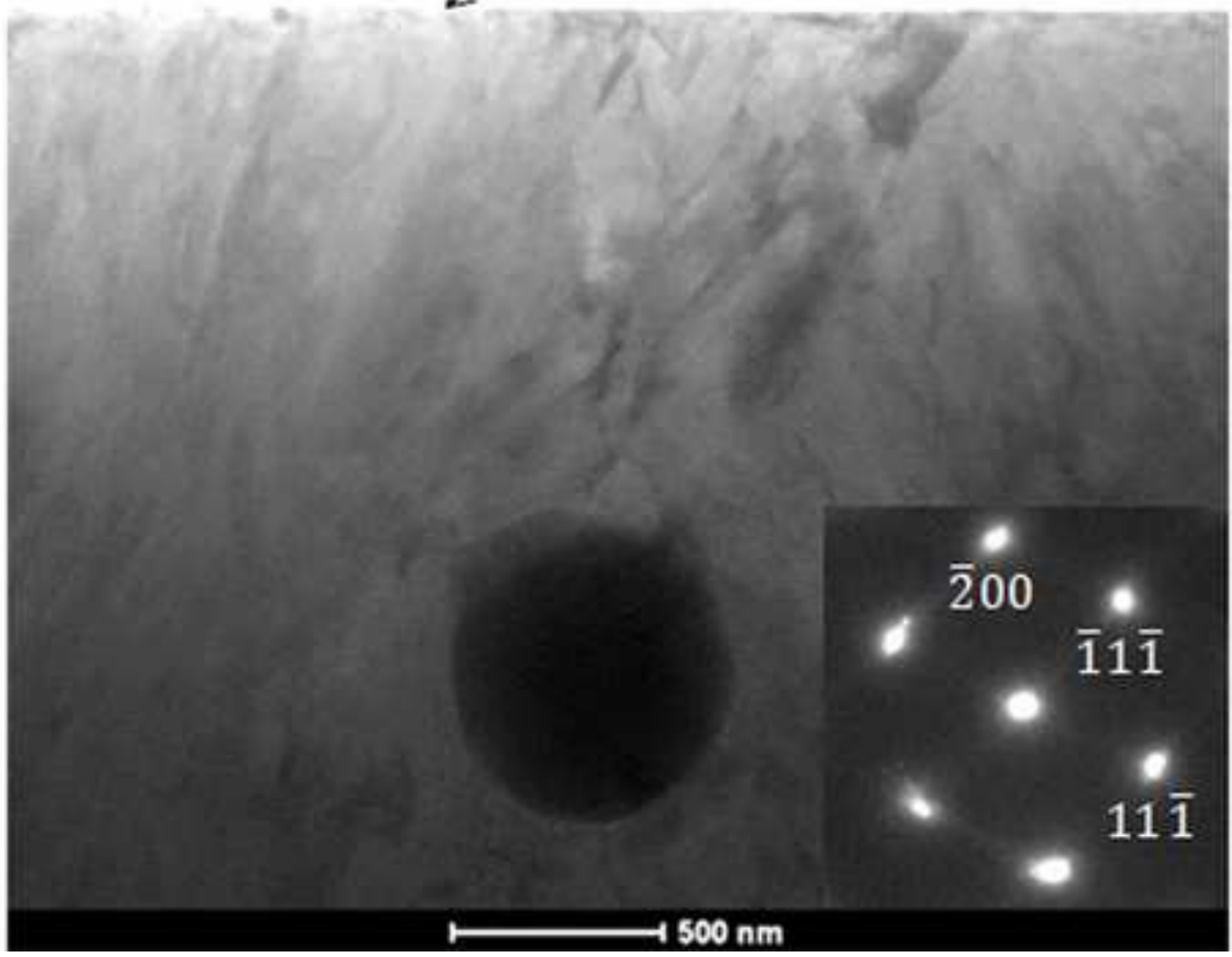


Figure 2
Click here to download high resolution image

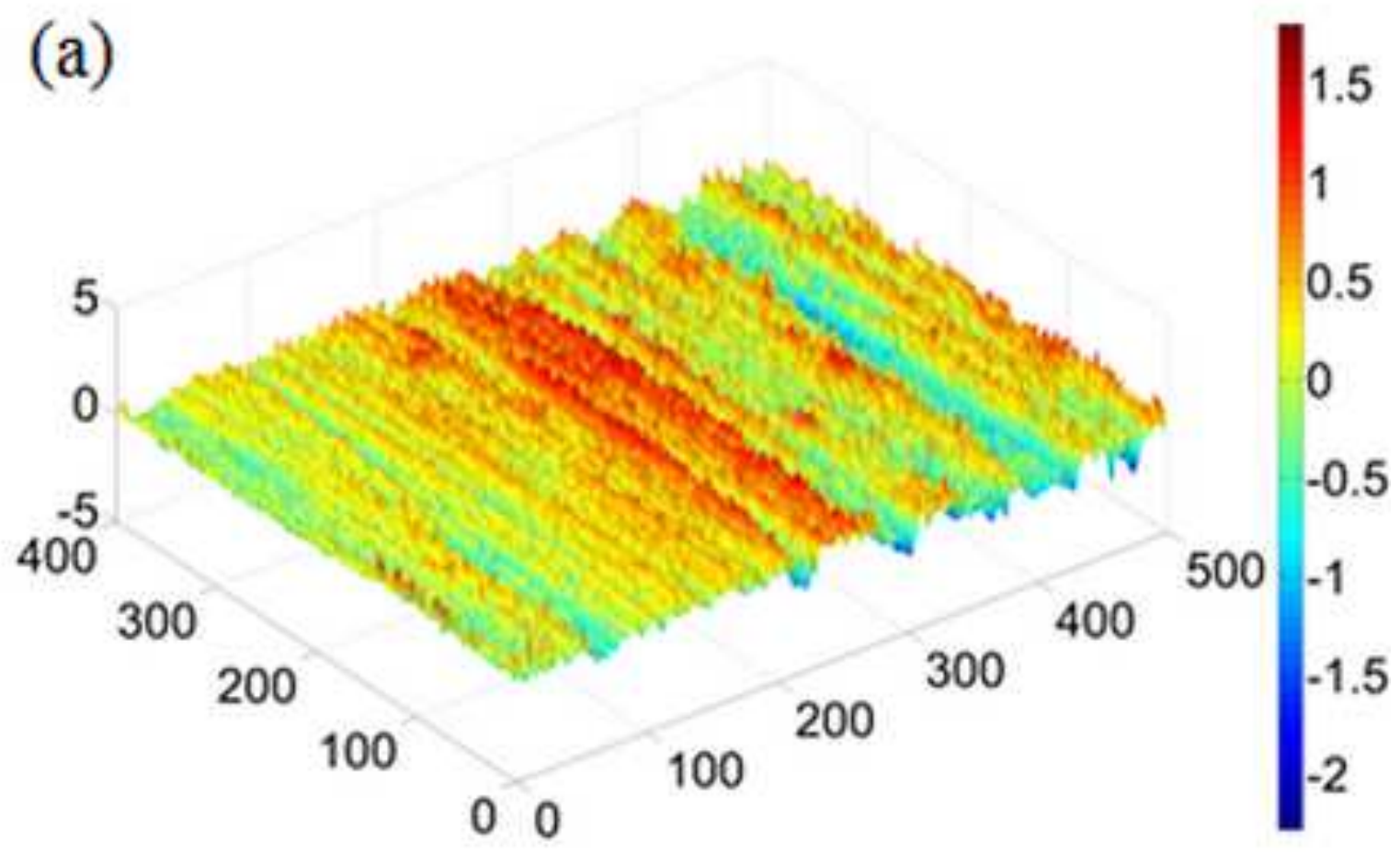

(b) polished surface 
Click here to download high resolution image
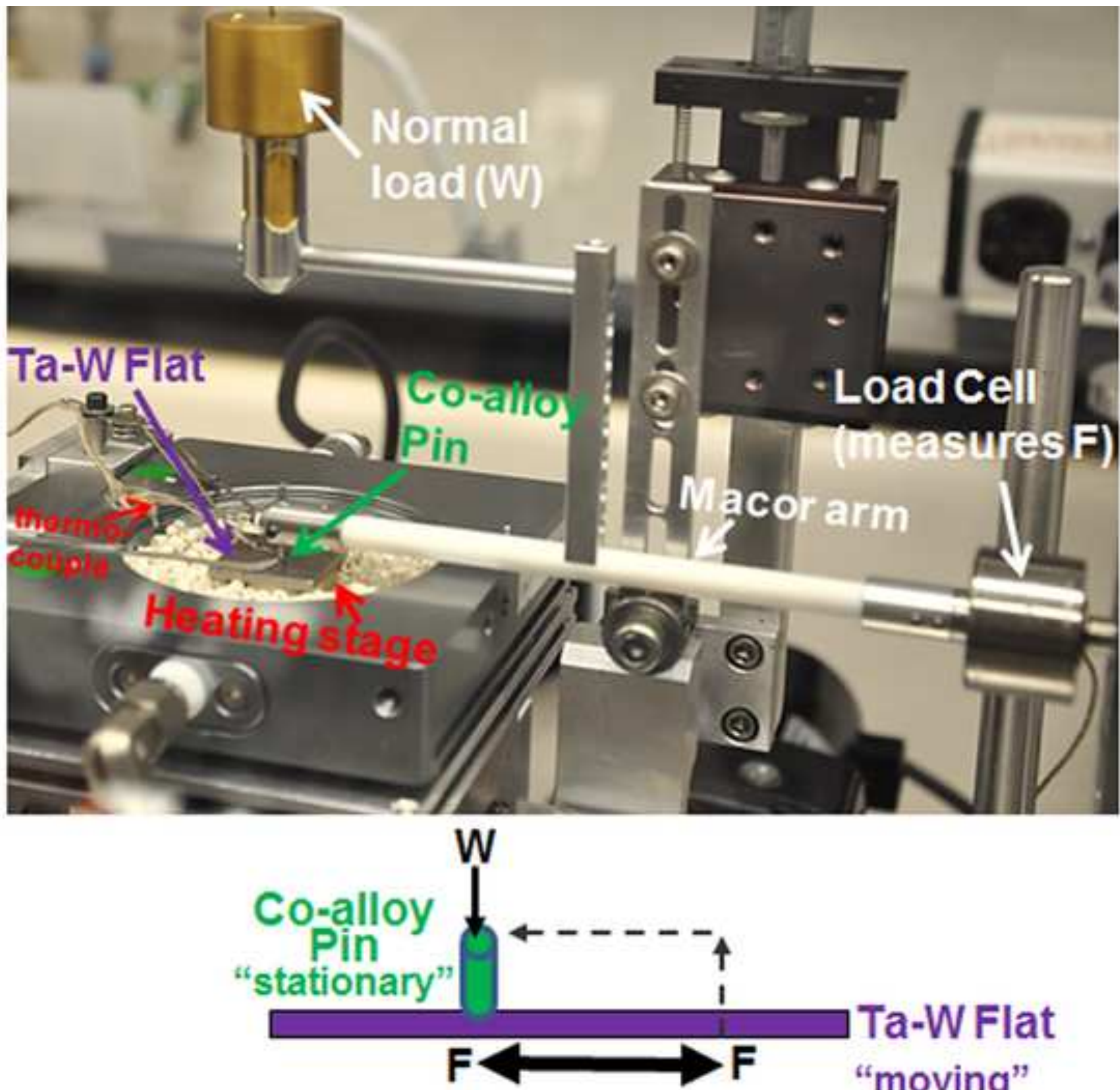

Ta-W Flat

"moving" 

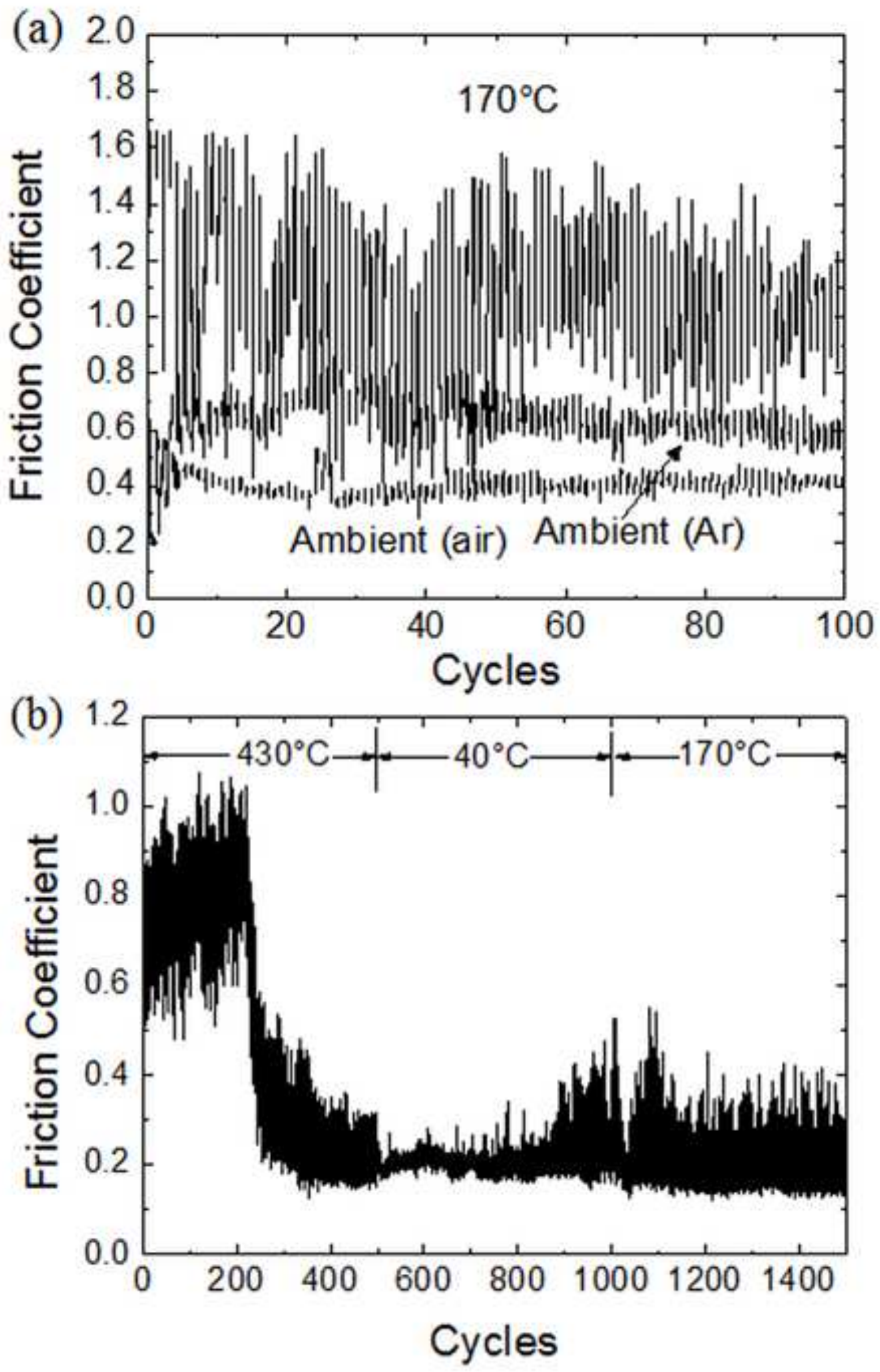


\section{gure 5}

Click here to download high resolution image

(a)

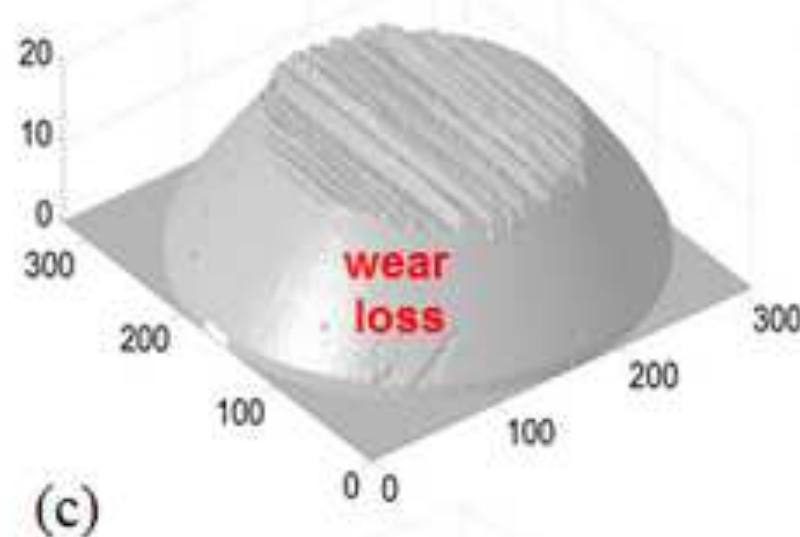

(c)

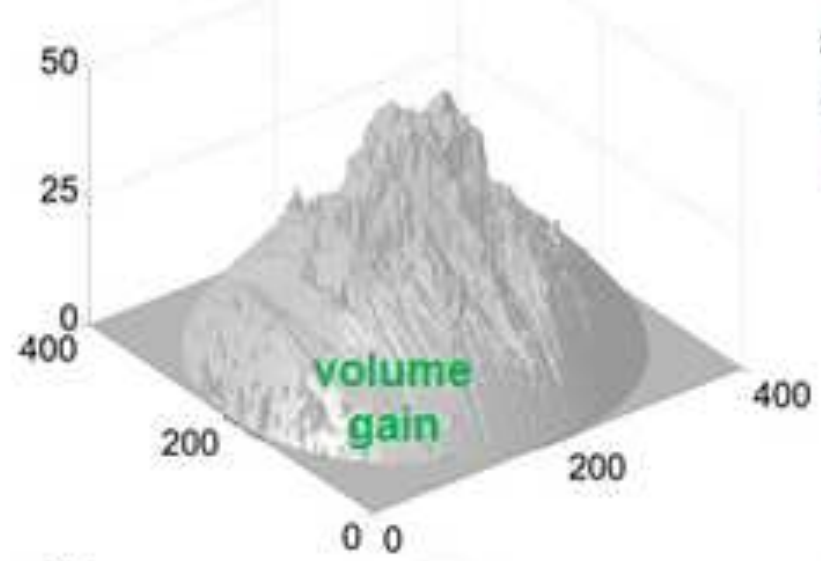

(e)

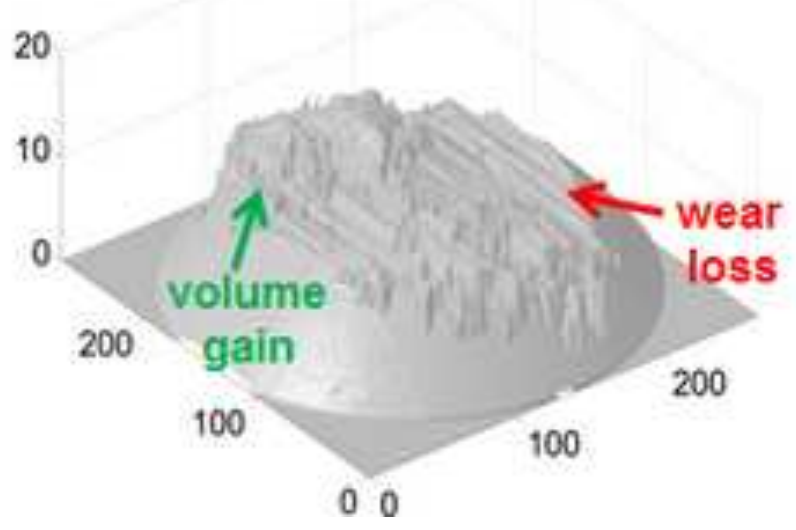

(b)

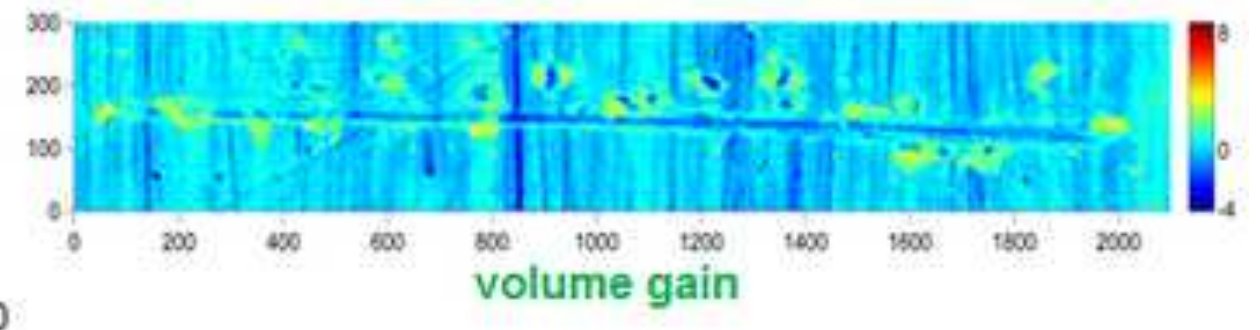

(d)

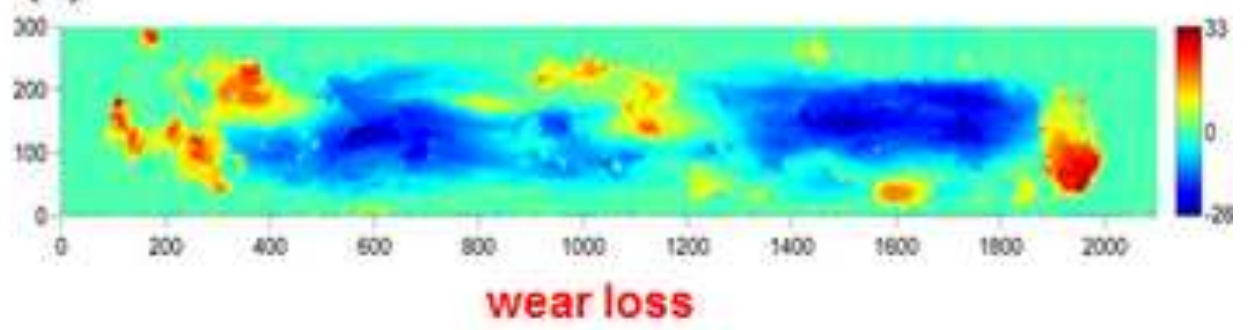

(f)

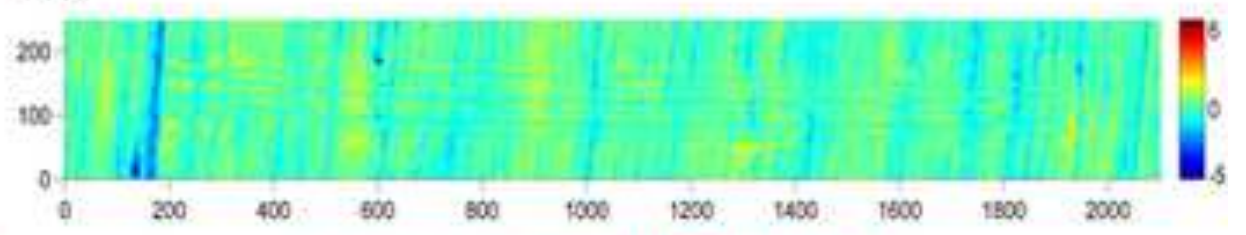
volume gain $\approx$ wear loss 


\section{Figure}

Click here to download high resolution image
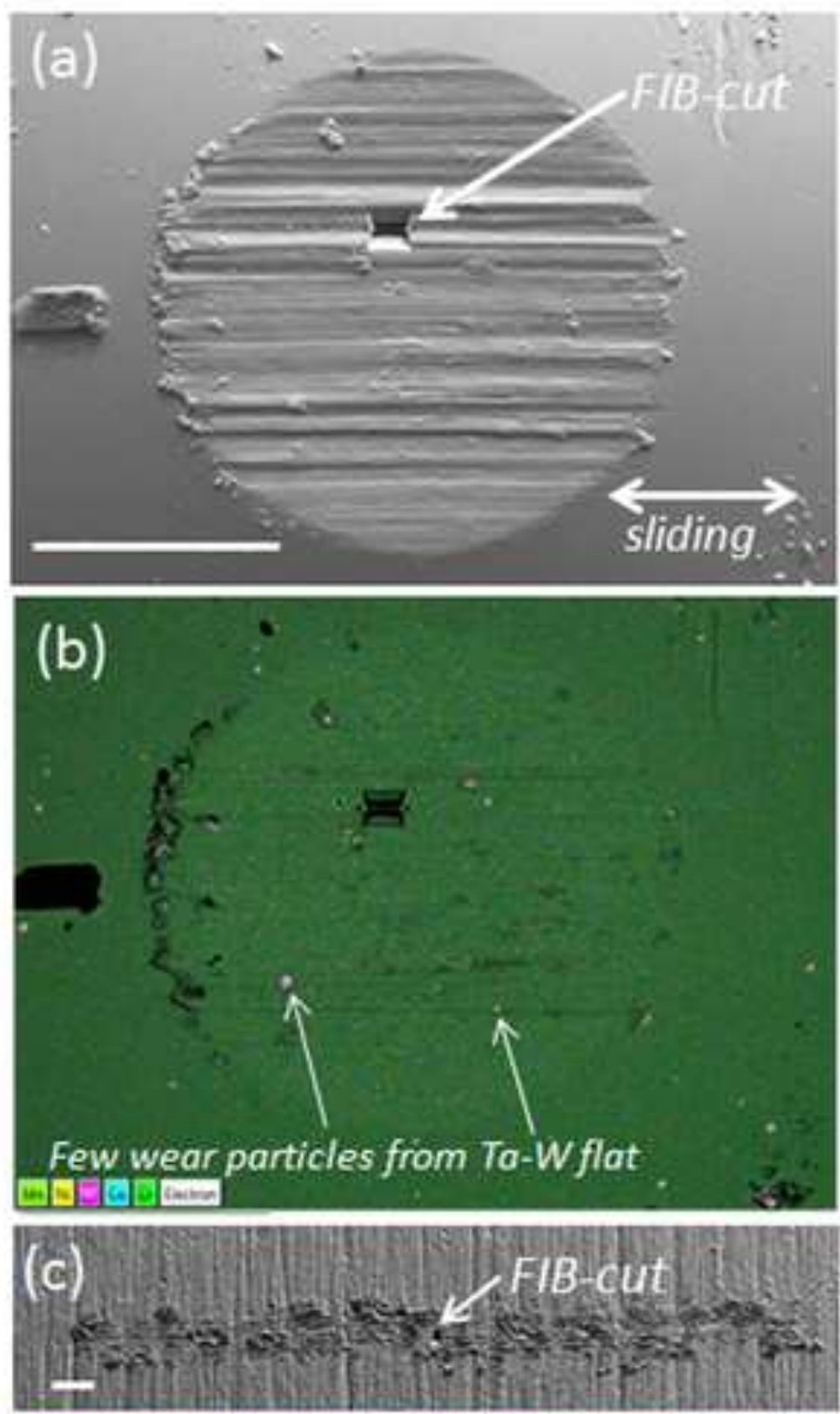

(d) Ta Ma

\section{Co K $\alpha$}

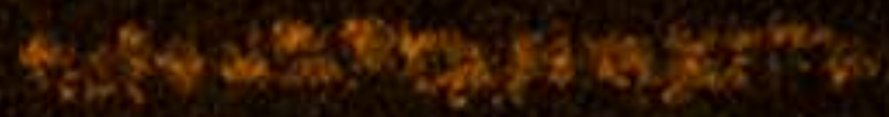

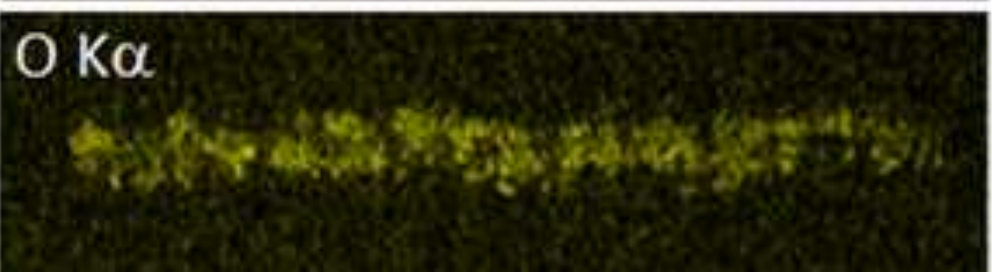




\section{Click here to download high resolution image}
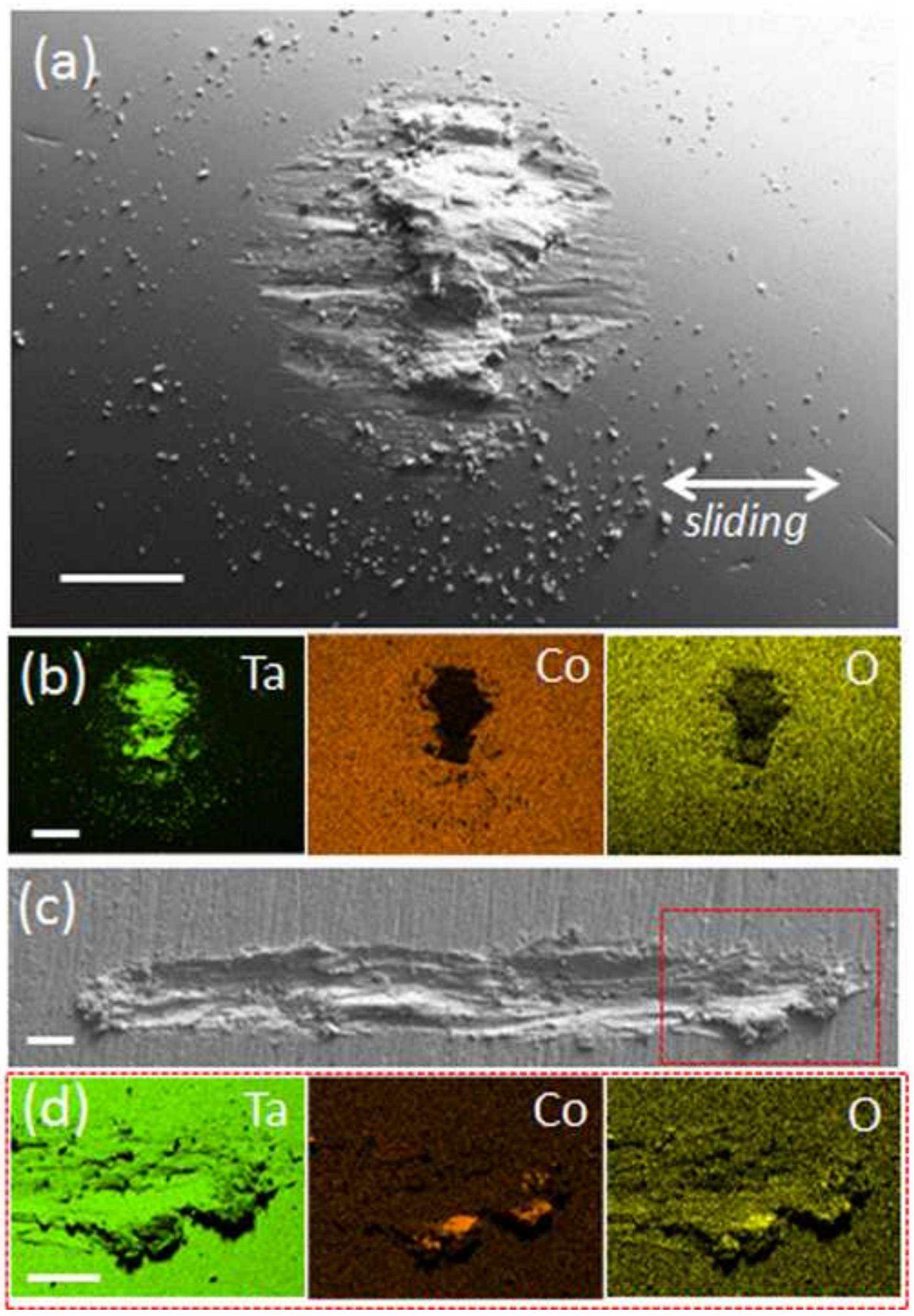
(a) .
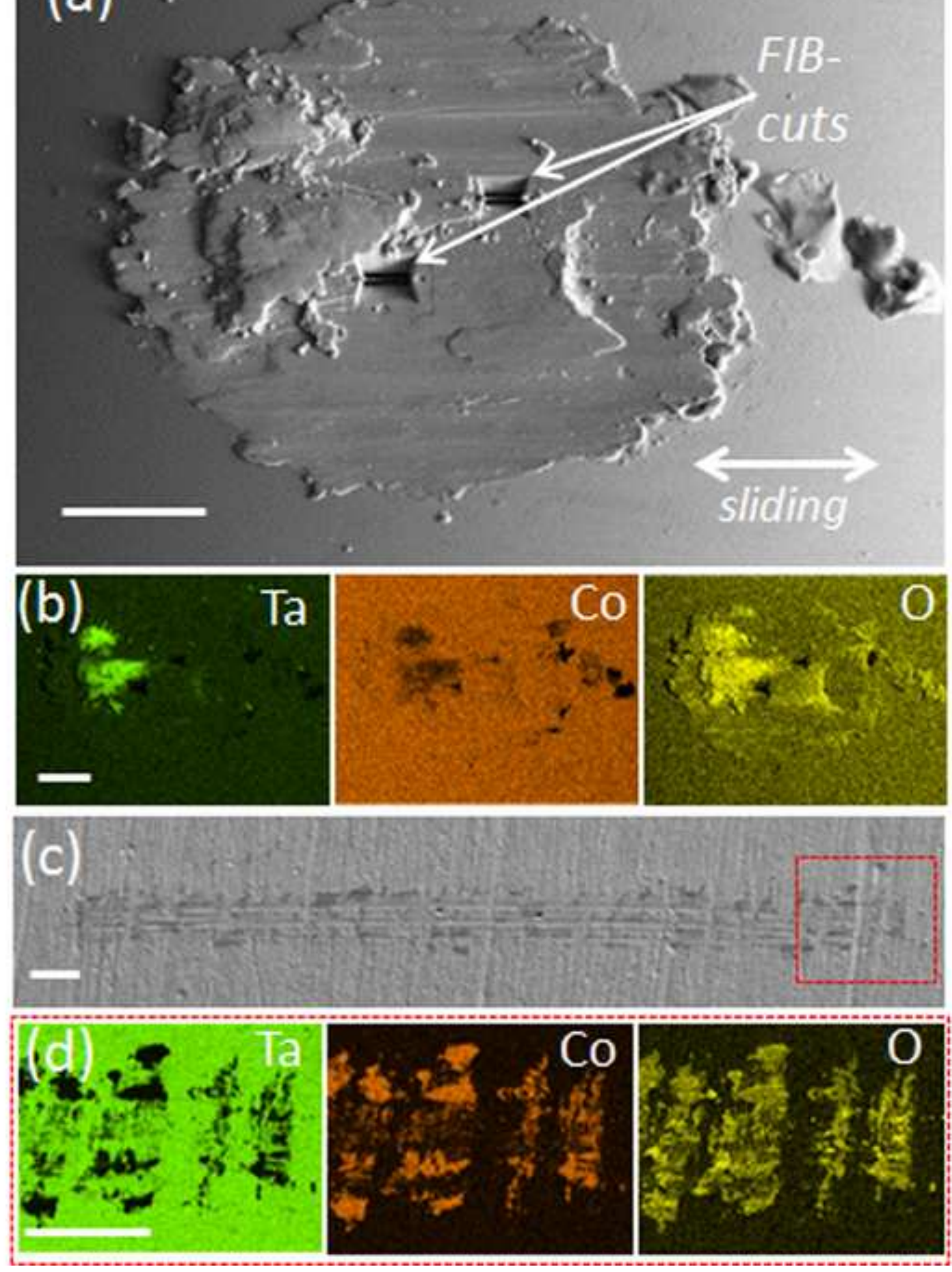
Click here to download high resolution image

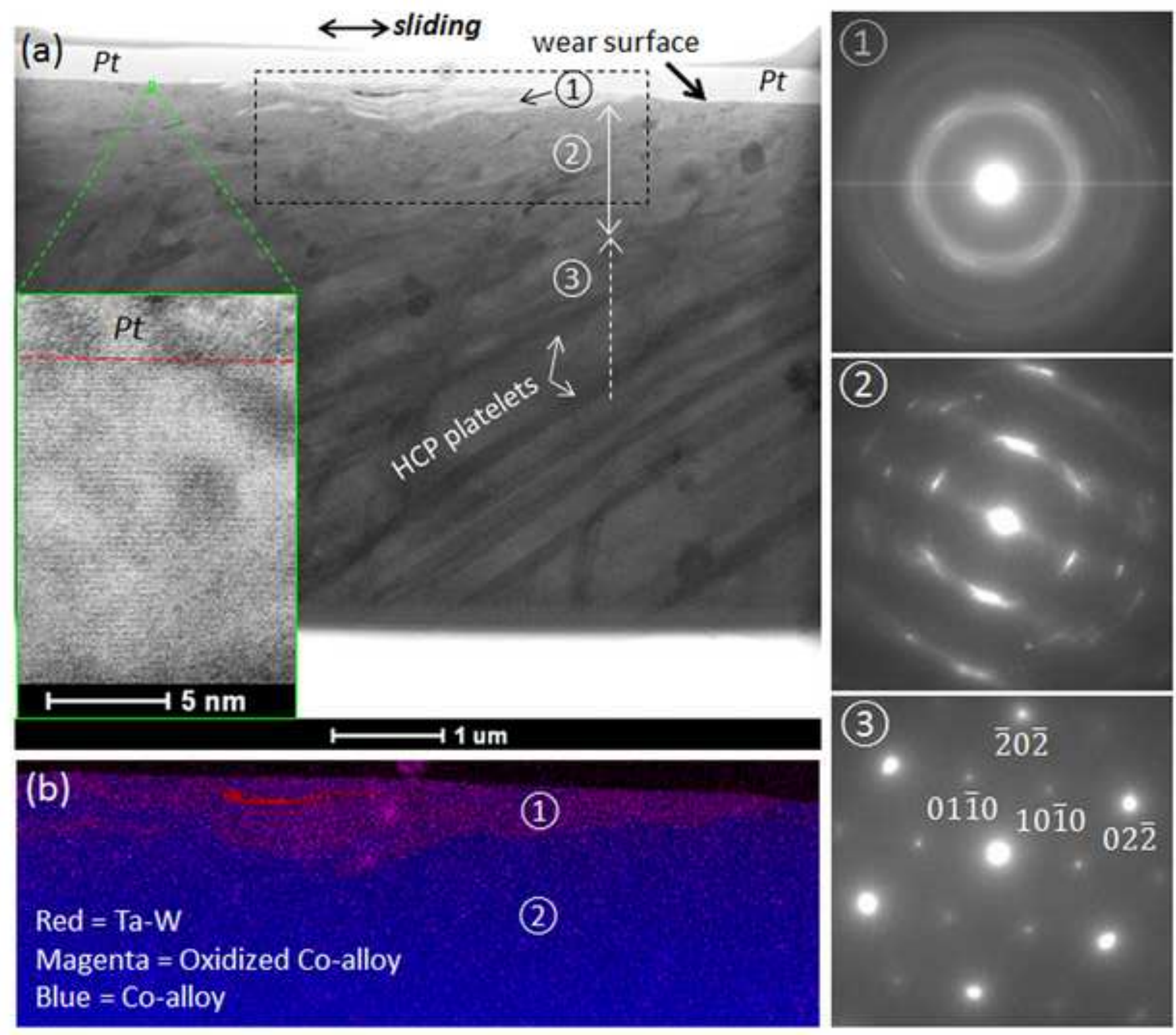

Click here to download high resolution imag 
Click here to download high resolution image
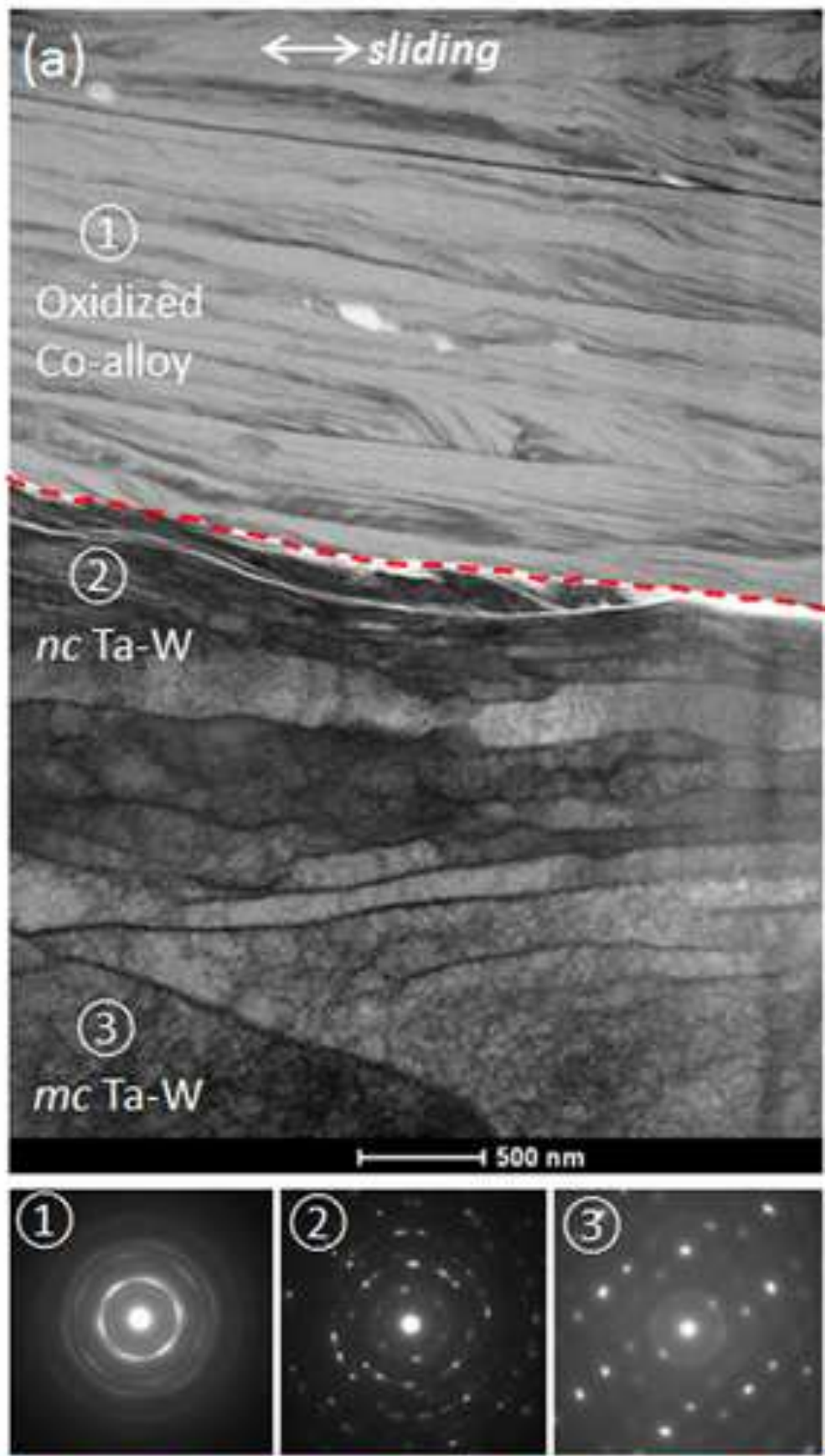

(b)

Magenta $=$ Oxidized Co-alloy $($ more 0$)$ Green $=$ Oxidized Co-alloy (less O) Red $=\mathrm{Ta}-\mathrm{W}$ 
Click here to download high resolution image
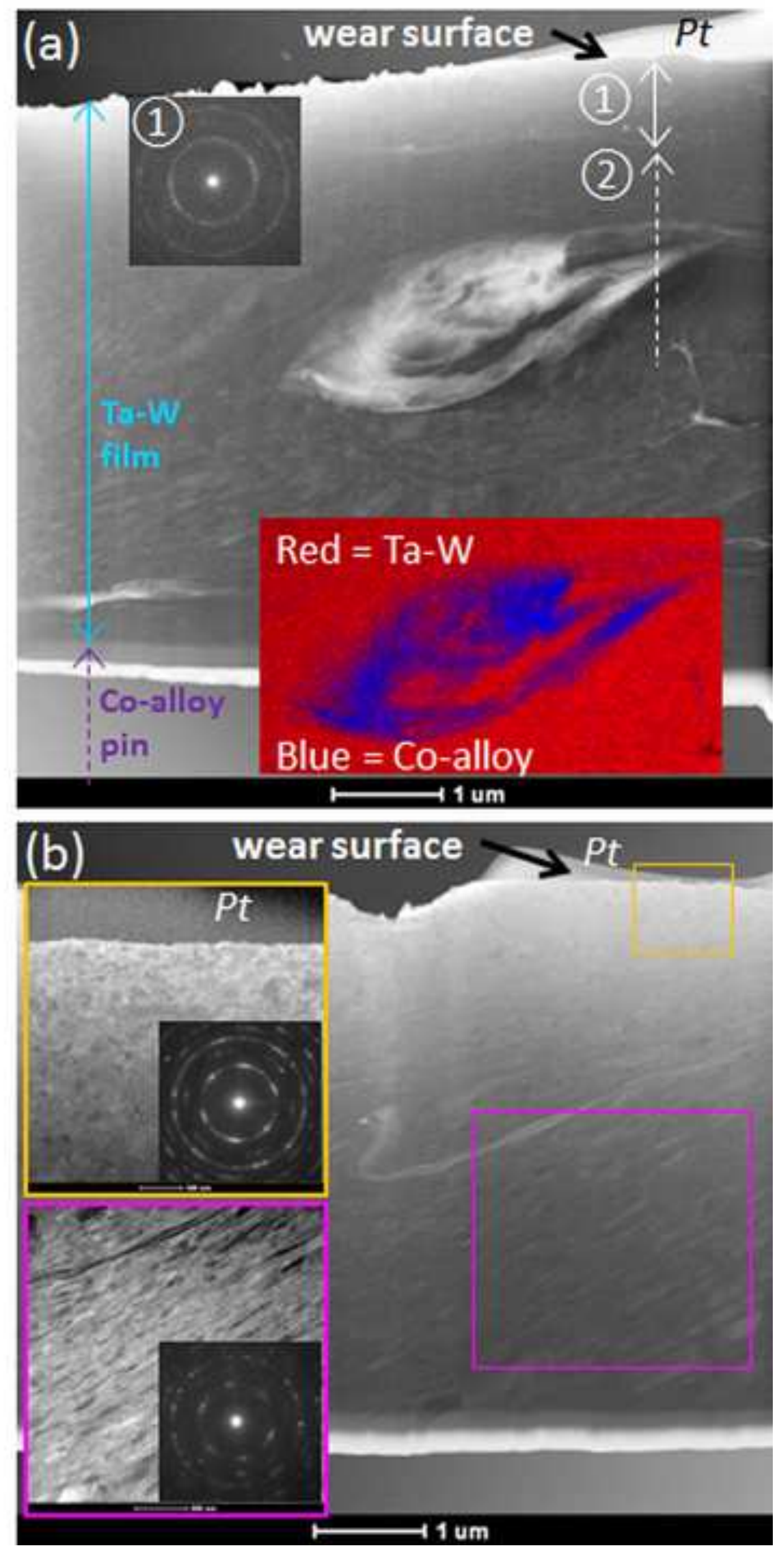
Figure 12

Click here to download high resolution image
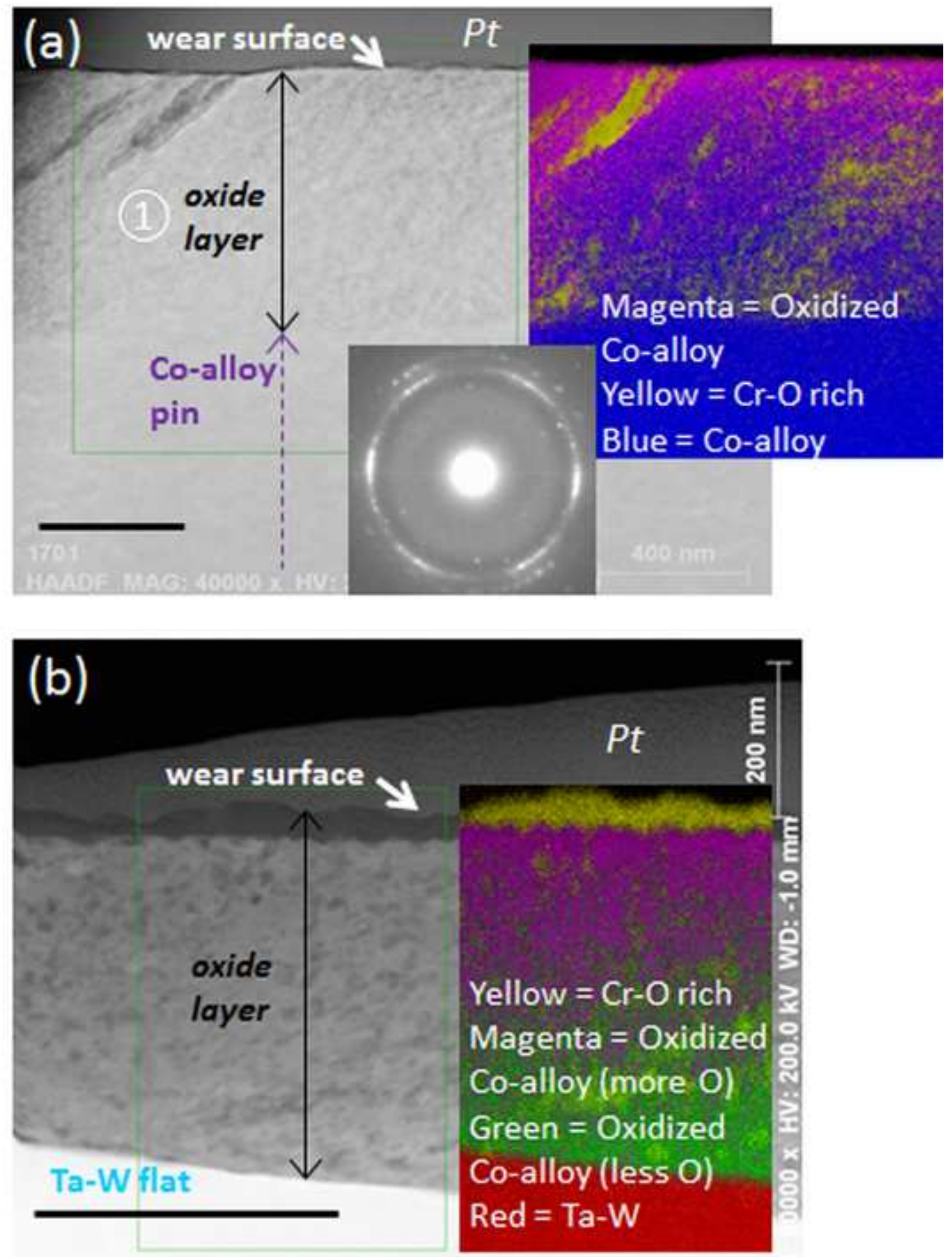